\title{
Retrospective Study of Dynamic Hip Screw Fixation in Intertrochanteric Fractures - Outcomes
}

\author{
Authors \\ Jaspal Singh $^{1}$, Partap Singh Verka ${ }^{2}$, Tapish Shukla ${ }^{3}$, Himanshu Agrahari ${ }^{4}$ \\ Mohit Singla ${ }^{5}$, Saurabh Jain ${ }^{6}$ \\ ${ }^{1}$ Professor, Department of Orthopaedics, Govt. Medical College, Amritsar, India \\ ${ }^{2}$ Professor and Head, Department of Orthopaedics, Govt. Medical College, Amritsar, India \\ ${ }^{3,4,5,6}$ Junior Resident, Department of Orthopaedics, Govt. Medical College, Amritsar, India \\ *Corresponding Author \\ Dr Partap Singh Verka \\ Professor and Head, Department of Orthopaedics, Govt. Medical College, Amritsar, India
}

\begin{abstract}
Background: Hip fracture contributes to both morbidity and mortality in the elderly.

The dynamic hip screw (DHS), commonly used in extramedullary fixation, has become a standard implant in treatment of these fractures. We conducted this study to investigate the efficacy of DHS fixation in treatment of intertrochanteric fractures.
\end{abstract}

Materials \& Methods: The plan was to study 50 cases of inter-trochanteric femur fractures of all types in Boyd and Griffin classification treated with Dynamic Hip Screw and to assess the outcome and the postoperative complications of it. Brief history and clinical examination was done according to the proforma attached. Radiological examination was done. Postoperative assessment was done. All the results were analyzed by SPSS software.

Results: In the DHS group, skin puckering with superficial infection was seen in 1 (2\%) patient. Cut-out was seen in 2 patients. Shortening was seen in $1(2 \%)$ patients. Mean TAD in the present study was found to be 23.98. Mean HHS at preoperative, 1 month postoperative, 2 month postoperative, 3 month postoperative and 6 month postoperative was 49.78, 60.96, 68.44, 74.28 and 82.12 respectively. Significant results were obtained while comparing the mean HHS among the patients of the DHS group at different time intervals. Conclusion: DHS still remains the gold standard for the treatment of stable intertrochanteric fractures in suitable patients. Therefore, we conclude that dynamic hip screw is a reliable, versatile and effective device for the treatment of intertrochanteric fractures

Keywords: Dynamic hip screw, Hip fracture.

\section{Introduction}

Hip fracture contributes to both morbidity and mortality in the elderly. The demographics of world populations are set to change, with more elderly living in developing countries. ${ }^{1}$
Inter trochanteric fractures of femur occur in the area between the greater and lesser trochanter and may involve these two structures. The goal of treatment of these fractures is stable fixation, which allows early mobilization of the patient. 
These fractures are associated with substantial morbidity and mortality. Associated co-morbid medical problem like diabetes, hypertension, pulmonary, renal and cardiac problems add to the insult of the fracture. ${ }^{2-4}$

Generally, intramedullary fixation and extramedullary fixation are the 2 primary options for treatment of such fractures. The dynamic hip screw (DHS), commonly used in extramedullary fixation, has become a standard implant in treatment of these fractures. ${ }^{5,6}$ Proximal femoral nail (PFN) and Gamma nail are 2 commonly used devices in the intramedullary fixation. Previous studies showed that the Gamma nail did not perform as well as DHS because it led to a relatively higher incidence of post-operative femoral shaft fracture. ${ }^{7}$

Although the effects of DHS in treatment of intertrochanteric fractures have been reported, the results and conclusions are not consistent. ${ }^{8}$ Therefore; we conducted this study to investigate the efficacy of DHS fixation in treatment of intertrochanteric fractures.

\section{Materials and Methods}

The plan was to study 50 cases of intertrochanteric femur fractures of all types in Boyd and Griffin classification treated with Dynamic Hip Screw and to assess the outcome and the postoperative complications of it. Medical records were deemed to be complete if in patient progress notes, outpatient follow up notes, intra op notes \& report of labs and radiological investigation were complete.

Despite being the treatment of choice for intertrochanteric fractures, DHS placement is not devoid of complications. Although such untoward incidents are infrequent, their consequences are devastating when they do occur.

Brief history and clinical examination was done according to the proforma attached. Radiological examination was done.

\section{Following Data Was Recorded}

1. Co-morbidities (Osteoporosis etc.)

2. Demographics
3. Type of fracture

4. Operative time

5. TAD(Tip-apex distance)

6. Post-operative complications (if any)-type of complication and subsequent revision

\section{Statistical analysis}

All the results were analyzed by SPSS software. Chi- square test and Mann Whitney $U$ test were used for assessment of level of significance. Pvalue of less than 0.05 was taken as significant.

\section{Results}

A total of 50 subjects were included in the present study. $12(24 \%)$ patients and $15(30 \%)$ patients of the DHS group belonged to the age group of 51 to 60 years, and 61 to 70 years respectively. 8 (16\%) patients and $8(16 \%)$ patients of DHS group belonged to the age group of 71 to 80 years and 31 to 40 years respectively. In the DHS group, union occurred on radiological examination after 18 weeks in $45(90 \%)$ patients while minimal union occurred in 5 (10\%) patients. In the DHS group, skin puckering with superficial infection was seen in $1(2 \%)$ patient. Cut-out was seen in 2 patients. Shortening was seen in $1(2 \%)$ patients. Mean TAD in the present study was found to be 23.98. Mean HHS at preoperative, 1 month postoperative, 2 month postoperative, 3 month postoperative and 6 month postoperative was $49.78,60.96,68.44,74.28$ and 82.12 respectively. Significant results were obtained while comparing the mean HHS among the patients of the DHS group at different time intervals. Mean blood loss among the subjects of the DHS group was found to be $292.50 \mathrm{ml}$ respectively. Mean duration of surgery in the patients of DHS group was found to be 63.36. Mean duration of hospital stay in the patients of DHS group was found to be 12.84 days. Mean time of early mobilization with toe touch weight bearing in the DHS group was found to be 41.3 weeks 
Table1: Distribution of subjects according to age

\begin{tabular}{|l|c|c|}
\hline \multirow{2}{*}{ Age group } & \multicolumn{2}{|c|}{ DHS group } \\
\cline { 2 - 3 } & Number of patients & Percentage \\
\hline $31-40$ & 8 & 16 \\
\hline $41-50$ & 7 & 14 \\
\hline $51-60$ & 12 & 24 \\
\hline $61-70$ & 15 & 30 \\
\hline $71-80$ & 8 & 16 \\
\hline Total & 50 & 100 \\
\hline Mean age $( \pm S D)$ & $60.14( \pm 13.09)$ \\
\hline
\end{tabular}

Table 2: Distribution of subjects according to gender

\begin{tabular}{|l|c|c|}
\hline \multirow{2}{*}{ Gender } & \multicolumn{2}{|c|}{ DHS group } \\
\cline { 2 - 3 } & Number of patients & Percentage \\
\hline Males & 22 & 44 \\
\hline Females & 28 & 56 \\
\hline Total & 50 & 100 \\
\hline
\end{tabular}

Table 3: Complications among patients of DHS group

\begin{tabular}{|l|c|c|}
\hline Type of & \multicolumn{2}{|c|}{ DHS } \\
\cline { 2 - 3 } Complication & No. of patients & Percentage \\
\hline $\begin{array}{l}\text { Skin puckering with } \\
\text { superficial infection }\end{array}$ & 1 & 2 \\
\hline Cut-out & 2 & 4 \\
\hline Shortening & 1 & 2 \\
\hline None & 46 & 92 \\
\hline
\end{tabular}

Table 4: TAD among subjects of the DHS group

\begin{tabular}{|l|c|}
\hline TAD & Value \\
\hline Mean & 23.98 \\
\hline SD & 2.03 \\
\hline Minimum & 22 \\
\hline Maximum & 29 \\
\hline
\end{tabular}

Table 5: Mean HHS among subjects of DHS

\begin{tabular}{|l|c|c|}
\hline HHS Score & DHS group & P-value \\
\hline Preoperative & 49.78 & \\
\cline { 1 - 2 } Postoperative 1 month & 60.96 & \multirow{2}{*}{0.00} \\
\cline { 1 - 2 } Postoperative 2 month & 68.44 & \\
\cline { 1 - 2 } Postoperative 3 month & 74.28 & \\
\cline { 1 - 2 } Postoperative 6 month & 82.12 & \\
\hline
\end{tabular}

Table 6: Descriptive results among DHS group patients

\begin{tabular}{|l|c|c|}
\hline Parameter & Mean & SD \\
\hline Blood loss & 292.50 & 9.12 \\
\hline Duration of surgery & 63.36 & 4.85 \\
\hline Hospital stay & 12.84 & 1.60 \\
\hline Time of early mobilization till & 41.3 & 4.48 \\
\hline
\end{tabular}




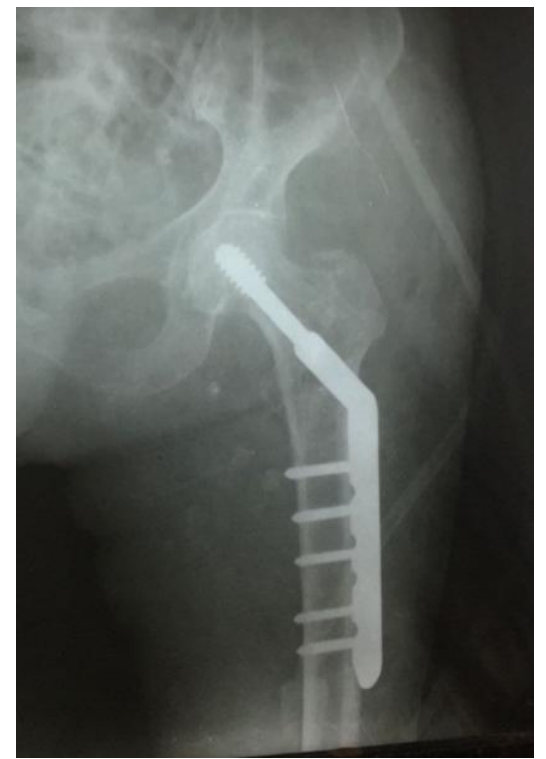

Immediate post op $x$ ray AP view

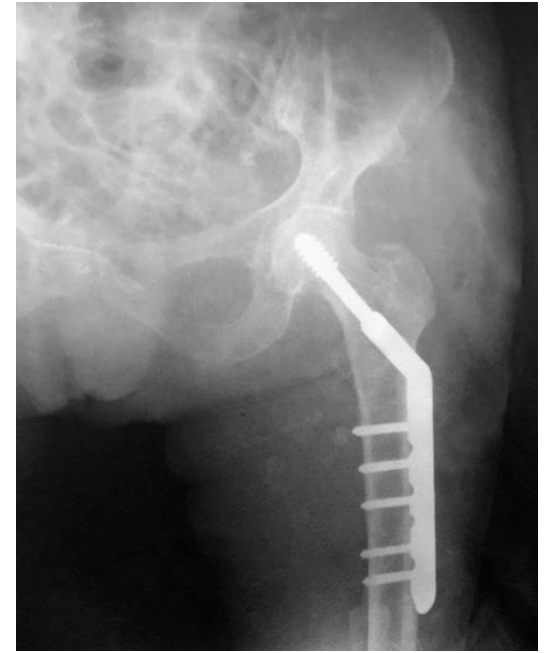

Radiological union after 18 weeks

\section{Functional outcome}

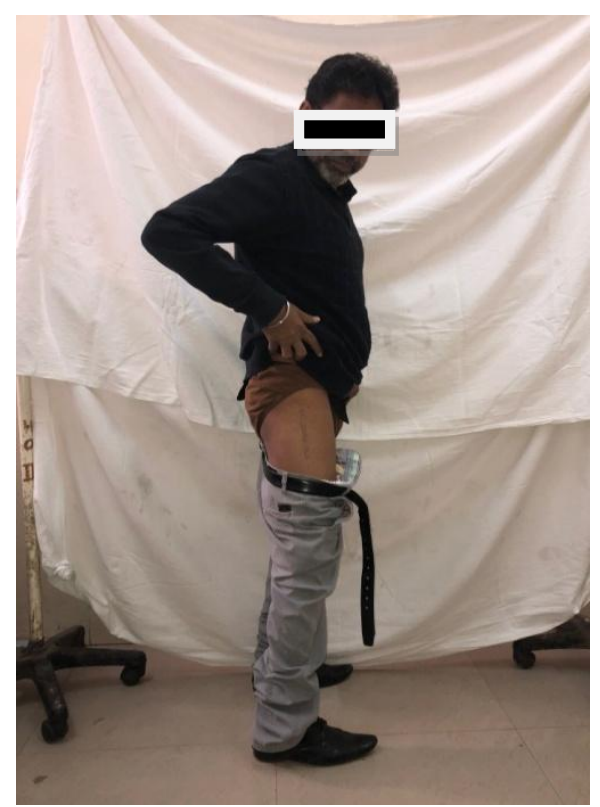

Standing

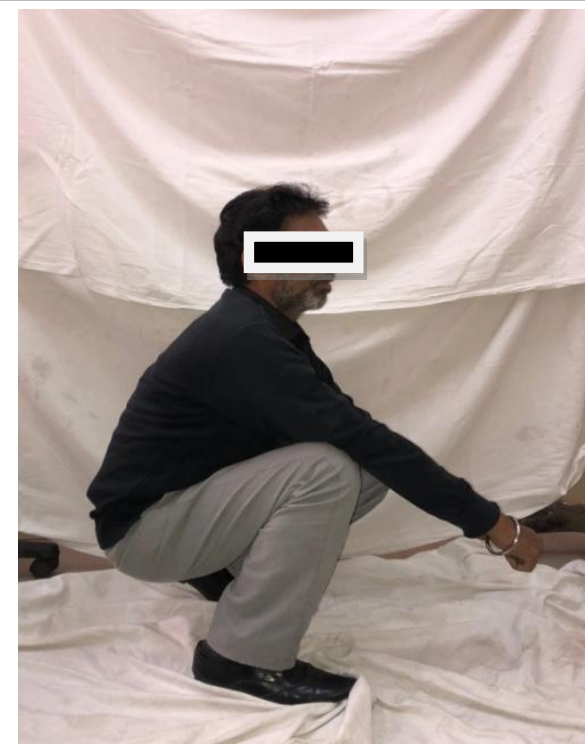

\section{Squatting}

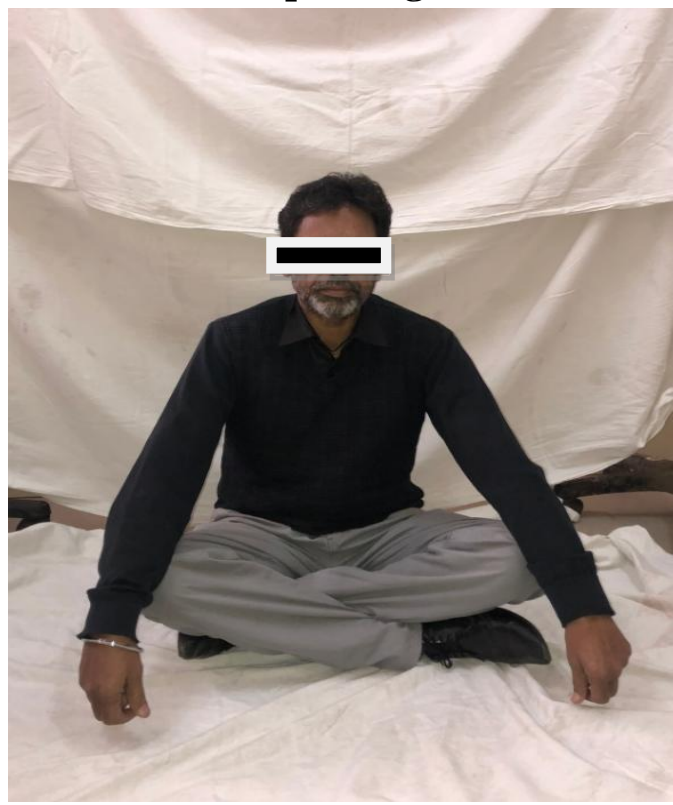

Cross legged

\section{Discussion}

Mean age of the present study population was 60.14 years and more than $70 \%$ of the study population was above the age of 50 years. Our results were in concordance with the results obtained by Sahu B et al and Jonnes et al, who reported the mean age of 62.5 years and 60 years in their respective studies. ${ }^{9,} 10$

The duration of surgery was calculated from the time of incision to skin closure. Our study shows that the average duration of surgery for DHS was 63.36 minutes. Our results were in concordance with results obtained by Sharma A et al (2017) who also observed similar findings in their study. Mean duration of surgery in the studies conducted 
by Sahu B et al and Ujjal Bhakat et al was 71.2 minutes and 69.3 minutes respectively. ${ }^{10-12}$

Mean blood loss in the DHS group was $292.5 \mathrm{ml}$. Our results were in concordance with the results obtained by Kumar R et al who also reported similar findings. ${ }^{30}$ Dynamic hip screw requires a relatively larger exposure, more tissue trauma and anatomical reduction. All these increase the morbidity, probability of infection and significant blood loss. (Kumar R et al.).Similar results were obtained in the studies of Ujjal Bhakat et al and Ranjeetesh Kumar et al who reported the mean blood loss of $213 \mathrm{ml}$ and $250 \mathrm{ml}$ respectively. ${ }^{12,13}$ The walking ability was assessed using Harris Hip Score. The mean Harris Hip Score in DHS group was 82.12 at 6 months. We observed a significant improvement in the mean HHS at progressive follow-ups. Our results were in concordance with the results obtained by Ujjal Bhakat et al and Ranjeeteshkumar et al who observed that mean HHS at final follow-up was 78.8 and 85 respectively. They also observed significant improvement in the mean HHS at progressive time intervals. ${ }^{12,13}$

Mean duration of hospital stay in the patients of DHS group was found to be 12.84 days. Mean duration of hospital stay in the studies conducted by Lee YS et al and Mundla MKR et al was 8.8 days and 17.13 days respectively. ${ }^{14,15}$

Mean TAD in the present study was 23.98. our results were in concordance with the results obtained by Chua YP et al, who reported that in their study, the average TAD was $22.55 \mathrm{~mm}$ (range: 6.22-58.66mm). Baumgaertner et al. first published information regarding the concept of TAD. In his series, the average TAD was $24 \mathrm{~mm}$ for the successfully treated fractures compared with $38 \mathrm{~mm}$ for those screw cut out group. There was a very strong statistical relationship between an increased TAD and the rate of cut out, regardless of other variables related to the fracture. $^{16,17}$

All the fractures in the dynamic hip screw group had united by 6 months one case of DHS with puckering of skin due to infection need minor surgery, one case of shortening and 2 cases of cutout. Our results were in concordance with the results obtained by Parker MJ, Schipper IB and Baumgaertner MR who also reported similar findings in their respective study. ${ }^{16-}{ }^{19}$ Previous studies have reported occurrence of avascular necrosis, non-union, fracture under the plate, screw breakage and pseudoarthorosis as potential complications in patients undergoing treatment with DHS. ${ }^{19}$

\section{Conclusion}

Several new alternative devices have been introduced and tried for the treatment of intertrochanteric fractures of the femur, in order to reduce or eliminate the risk of postoperative complications using DHS. But, DHS still remains the gold standard for the treatment of stable intertrochanteric fractures in suitable patients. Therefore, we conclude that dynamic hip screw is a reliable, versatile and effective device for the treatment of intertrochanteric fractures

\section{References}

1. Dhanwal DK, Dennison EM, Harvey NC, Cooper C. Epidemiology of hip fracture: Worldwide geographic variation. Indian Journal of Orthopaedics. 2011;45(1):1522.

2. Gulberg B, Johnell O, Kanis JA. Worldwide projection for hip fractures. Osteoporos Int. 1997;7(5):407-13.

3. Cooper A. A Treatise on Dislocations and Fractures of the Joints. London, England: Longman, Hurst, Rees, Orme and Brown; 1822.

4. Mittal R, Banerjee S. Proximal femoral fractures: Principles of management and review of literature. J Clinic Orthopaed Traum. 2012;3(1):15-23.

5. Evans EM. The treatment of intertrochanteric fractures of the femur. JBJS 1949;31-B:190-203. 
6. Langenbeck B. Description of transfixion of femoral head by a transtrochantericnail (transl) Verh Dtsch Ges Chir. 1878;1:92.

7. Smith-Petersen M. Treatment of fractures of the neck of the femur by internal fixation. Surg Gynecol Obstet. 1937;64:287.

8. Tencer AF, Johnson KD. Biomechanics in Orthopaedictrauma: bone fracture and fixation. London: Martin Dunitz,1994.

9. Jonnes C, SM S, Najimudeen S. Type II Intertrochanteric Fractures: Proximal Femoral Nailing (PFN) Versus Dynamic Hip Screw (DHS). Archives of Bone and Joint Surgery. 2016;4(1):23-28.

10. Jonnes C, SM S, Najimudeen S. Type II Intertrochanteric Fractures: Proximal Femoral Nailing (PFN) Versus Dynamic Hip Screw (DHS). Archives of Bone and Joint Surgery. 2016;4(1):23-28.

11. Sharma A, Sethi A, Sharma S. Treatment of stable intertrochanteric fractures of the femur with proximal femoral nail versus dynamic hip screw: a comparative study. RevistaBrasileira de Ortopedia (English Edition). Available online 8 November 2017. In Press, Uncorrected Proof. Doi: https://doi.org/10.1016/j.rboe.2017.07.008

12. Bhakat U, Bandyopadhayay R. Comparitive Study between Proximal Femoral Nailing and Dynamic Hip Screw in Intertrochanteric Fracture of Femur. Open Journal of Orthopedics, 2013, 3, 291-295.

13. Kumar R, Singh RN, Singh BN. Comparative prospective study of proximal femoral nail and dynamic hip screw in treatment of intertrochanteric fracture femur. Journal of Clinical Orthopaedics and Trauma. 2012;3(1):2836.

14. Lee YS, Huang HL, Lo TY, Huang CR. Dynamic hip screw in the treatment of intertrochanteric fractures: a comparison of two fixation methods. IntOrthop. 2007 Oct; 31(5): 683-688.

15. Mundla MKR, Shaik MR, Buchupalli SR, Chandranna B. A prospective comparative study between proximal femoral nail and dynamic hip screw treatment in trochanteric fractures of femur. Int J Res Orthop. 2018Jan;4(1):58-64.

16. Baumgaertner MR, Curtin SL, Lindskog DM. Intramedullary versus extramedullary fixation for the treatment of intertrochanteric fractures. Clin Orthop Relat Res. 1998;348:87-94.

17. Chua YP, Kwan MK, Ng WM, Saw A. Use of the Tip-Apex Distance in predicting Dynamic Hip Screw Cut Out in Intertrochanteric Fracture of the Femur in Asian Population. Malaysian Orthopaedic Journal. 2011; 5(2): 24-27.

18. Schipper IB, Steyerberg EW, Castelein $\mathrm{RM}$, et al. Treatment of unstable trochanteric fractures. Randomised comparison of the gamma nail and the proximal femoral nail. J Bone Joint Surg Br. 2004;86:86-94.

19. Hrubina M1, Skoták M, Běhounek J. Complications of dynamic hip screw treatment for proximal femoral fractures. Acta Chir Orthop Traumatol Cech. 2010 Oct;77(5):395-401. 